\title{
Pemanfaatan Vertical Garden Sebagai Alternatif Solusi Ketersediaan Pangan Masyarakat
}

\author{
Zulpi Miftahudin, Randy Fadillah Gustaman, Dede Wahyu Firdaus, \\ Setio Galih Marlyono \\ Universitas Siliwangi \\ Email: setiogeo@unsil.ac.id
}

\begin{abstract}
Abstrak
Tujuan pengabdian ini adalah mengedukasi masyarakat akan Ketahanan Pangan, dalam hal ini secara spesifiknya adalah dengan membangun Vertical Garden sebagai solusi alternative pemenuhan kebutuhan pangan masyarakat perkotaan dalam era New Normal Covid-19. Lokasi pengabdian adalah di Kelurahan Setiamulya Kecamatan Tamansari Kota Tasikmalaya. Bentuk kegiatan pengabdian ini adalah berbasis kemitraan dengan menggunakan kaji tindak (action research) dengan menggunakan pendekatan andragogy yaitu Pendidikan orang dewasa dengan jenis pelatihan berupa workshop. Metode utama yang digunakan dalam pelatihan adalah demontrasi, simulasi, dan praktek pemasangan vertical garden. Siklus pengabdiannya terdiri dari dua siklus, siklus pertama yaitu (1) Orientasi pelatihan, (2) Pemaparan materi terkait vertical garden, (3) Workshop pembuatan vertical garden, (4) Refleksi ketercapaian target pelatihan siklus pertama. Sedangkan siklus kedua terdiri dari (1) Penyampaian refleksi siklus pertama, (2) Workshop perbaikan dan penyempurnaan vertical garden, (3) Refleksi ketercapaian target pelatihan siklus kedua. Khalayak sasaran dari pengabdian ini adalah masyarakat di Kelurahan Setiamulya Kecamatan Tamansari Kota Tasikmalaya yang dipilih secara random sampling sebanyak 5 rumah (menyesuaikan dengan biaya pengabdian). Target luaran dan dampak yang ingin dicapai oleh pengabdian ini adalah terbinanya masyarakat yang mengerti dan dapat memanfaatkan vertical garden untuk kebutuhan pangan sehari-hari ditengah pandemic covid19 ini.
\end{abstract}

Kata kunci : Vertical Garden, Ketersediaan Pangan, Masyarakat

\begin{abstract}
Siliwangi University as an educational institution has an obligation to serve the community as stated in the Tri Dharma of the University. The form of service that will be proposed is to educate the public about Food Security, in this case specifically by building a Vertical Garden as an alternative solution to meet the food needs of urban communities in the New Normal Covid-19 era. The location of the service is in Setiamulya Village, Tamansari District, Tasikmalaya City. The form of this service activity is partnership-based using action research using the andragogy approach, namely adult education with the type of training in the form of workshops. The main methods used in the training are demonstrations, simulations, and the practice of installing a vertical garden. The service cycle consists of two cycles, the first cycle is (1) training orientation, (2) presentation of material related to vertical garden, (3) vertical garden making workshop, (4) reflection on the achievement of the first cycle training target. While the second cycle consists of (1) Delivering the reflection of the first cycle, (2) Workshop on repairing and perfecting the vertical garden, (3) Reflecting on the achievement of the second cycle of training targets. The target audience of this service is the people in Setiamulya Village, Tamansari District, Tasikmalaya City who were selected by random sampling of 5 houses (adjusting for service costs). The output target and impact that this service wants to achieve is the development of a community who understands and can take advantage of the vertical garden for daily food needs amid the Covid-19 pandemic.
\end{abstract}

Keywords: Vertical Garden, Food Availability, Community

\section{PENDAHULUAN}

Indonesia adalah negara kepulauan yang memiliki beribu-ribu pulau dan beragam potensi alam yang sangat berlimpah. Sebagai negara kepulauan, sudah sewajarnya Indonesia sangat berlimpah ruah kekayaan alam laut yang dapat mencukupi masyarakatnya, yang karena itulah banyak mata pencaharian masyarakat Indonesia adalah sebagai nelayan. 
Selain kekayaan yang ada di lautan, kekayaan alamnya terdapat pula baik di atas permukaan tanah maupun dibwah permukaan tanah. Indonesia memiliki rangkaian pegunungan api sirkum pasifik dan sirkum mediterania yang menyebabkan tanah Indonesia menjadi sangat subur karena memiliki banyak unsur hara vulkanik. Kesuburan tanah tersebut tentunya menjadi modal yang sangat baik bagi pengembangan lahan pertanian dan perkebunan. Alhasil banyak masyarakat di Indonesia yang berprofesi sebagai petani.

Basic profesi masrarakat Indonesia yang mayoritas nelayan dan petani memupuk banyak budaya rasa gotong-royong, saling bantu membantu dalam segala permasalahan yang terjadi. Selain itu masyarakat Indonesia terkenal sangat religius dengan berbagai agama dan kepercayaan yang dianutnya. Kondisi alam yang subur serta mata pencaharian mayoritas masyarakatnya adalah nelayan dan petani, sudah seharusnya masyarakat tercukupi secara ketahanan pangan. Kondisi ketahanan pangan yang seharusnya sudah terjamin, tidak sepenuhnya tercapai, terutama setelah munculnya pandemic covid-19 akhirakhir ini. Munculnya pandemic Covid-19 pada awal tahun 2020 sangat dirasakan dampaknya bagi seluruh dunia, terutama mengenai bahaya penyakitnya yang dapat menghilangkan nyawa seseorang dalam beberapa saat saja. Dampak lainnya adalah seluruh sector sendi kehidupan berhenti di seluruh dunia, aktifitas keluar rumah dibatasi, alhasil sector ekonomi mengalami kemunduran yang signifikan.

Di Indonesia, sampai pada tanggal 16 Juni 2020, jumlah orang yang positif covid 19 mencapai 39.294 orang, yang sembuh 15.123 orang, dan yang meninggal dunia sebanyak 2.198 orang. Kota Tasikmalaya sebagai salah satu kota di Jawa Barat tidak luput dari dampak covid tersebut. Menurut data tanggal 21 Mei 2020 korban covid-19 yang positif di Kota Tasikmalaya sudah mencapai 46 orang, hal tersebut tentulah sangat menghawatirkan. Data tersebut terus bertambah seiring waktu berjalan, dan mau tidak mau karena PSBB (Pembatasan Sosial Berskala Besar) dianggap kurang efektif, maka diberlakukan New Normal, dimana sendi kehidupan perlahan dibuka demi keberlangsungan perekonomian agar dapat bergulir.

Pada Era New Normal ini masyarakat diharapkan mampu untuk mencukupi segala kebutuhan kehidupannya ditengah segala keterbatasan, terutama akses pekerjaan yang terbatas, yang menyebabkan penghasilan menjadi menurun, dan tentunya daya beli juga ikut menurun. Mengatasi permasalahan tersebut, dalam rangka menyongsong New Normal, maka segala macam antisipasi terus digalakan agar masyarakat dapat menjalani situasi tersebut dengan siap dan maksimal.

Salah-satu permasalahan yang muncul mengenai ketahanan pangan adalah semakin berkurangnya lahan pertanian untuk dapat dimanfatatkan dalam mencukupi kebutuhan pangan sehari-hari ditengah segala keterbatasan situasi pandemic covid-19. Permasalahan tersebut sangat banyak dirasakan di masyarakat kota pada khususnya, karena sudah banyak alih fungsi lahan pertanian ke pemukiman atau peruntukan lainnya yang menyebabkan hilangnya tempat bercocok tanam.

Universitas Siliwangi sebagai institusi Pendidikan memiliki kewajiban pengabdian terhadap masyarakat sebagaimana tercantum dalam Tri Dharma Universitas. Bentuk pengabdian yang akan diajukan sebagai solusi pemecahan permasalahan yang terjadi adalah mengedukasi masyarakat akan Ketahanan Pangan, dalam hal ini secara spesifiknya adalah dengan mengedukasi mengenai pembuatan Vertical Garden sebagai solusi alternative pemenuhan kebutuhan pangan masyarakat perkotaan.

Vertical garden pertama kali diperkenalkan di Prancis pada tahun 1994 oleh ahli botani bernama Patrick Blanch, yang dilatatbelakangi oleh semakin berkurangnya lahan karena proses pembangunan ${ }^{1}$. Menurut beliau konsep vertical garden mempunyai banyak kelebihan, terutama ruang tanamnya akan lebih lebih besar dibandingkan dengan konsep konvensional yang memakan lahan horizontal yang lebih luas. Pengaplikasian vertical garden tersebut dapat dilakukan dibeberapa sudut bangunan baik indoor maupun outdoor, seperti pagar, carport, serta dinding-dinding pembatas lainnya, sehingga dapat terlihat lebih indah 
dan tidak monoton. Kesadaran masyarakat akan lingkungan yang bersih, yang nyaman serta aman semakin meningkat ${ }^{2}$.

Vertical garden adalah tanaman yang dapat ditanam dan tumbuh secara langsung pada bagian sisi luar bangunan dengan menggunakan system struktur yang terpisah sehingga dapat diberdirikan atau ditempelkan pada dinding ${ }^{3}$. Selain fungsinya sebagai pemanfaatan lahan sempit, vertical garden juga dapat membuat udara di sekitar menjadi sejuk. Vertical garden dapat mempunyai peranan penting dalam iklim perkotaan, sehingga lebih sejuk, selain fungsi lainnya sebagai ketersediaan kebutuhan pangan ${ }^{4}$. Hal tersebut tentunya dapat menjadi solusi ditengah daya beli masyarakat yang menurun dapat disiasati dengan hasil produksi vertical garden dalam bentuk pangan untuk memenuhi kebutuhan sehari-hari. Maka tujuan dari kegiatan pengabdian yakni mengedukasi masyarakat akan Ketahanan Pangan, dalam hal ini secara spesifiknya adalah dengan membangun Vertical Garden sebagai solusi alternative pemenuhan kebutuhan pangan masyarakat perkotaan dalam era New Normal Covid-19.

\section{BAHAN DAN METODE}

Bentuk kegiatan pengabdian ketahanan pangan berbasis kemitraan ini akan menggunakan Bentuk kegiatan berbasis kemitraan ini akan menggunakan kaji tindak (action research) dengan pendekatan andragogy yaitu pendidikan orang dewasa dengan jenis pelatihan berupa workshop. Metode utama dalam pelatihan adalah demostrasi, simulasi, dan praktik pembuatan dan pemasangan vertical garden.

Pengabdian ini melibatkan pihak mitra yaitu Pemerintah setempat dalam hal ini adalah Kelurahan. Lokasi pengabdian adalah di Kelurahan Setiamulya Kecamatan Tamansari Kota Tasikmalaya, karena pada kelurahan tersebut sudah cukup padat penduduk, dan lahan pertaniannya sudah banyak berkurang serta beralih fungsi menjadi peruntukan lain. Solusi dari kurangnya lahan pertanian tersebut adalah dengan memanfaatkan lahan sempit dengan cara vertical garden. Berdasarkan pemaparan tersebutlah maka proposal pengajuan Pengabdian ini mengambil judul "Pemanfaatan Vertical Garden Sebagai Alternatif Solusi Ketersediaan Pangan Masyarakat".

Masyarakat yang menjadi sasaran adalah Masyarakat yang berada di Kelurahan Setiamulya Kecamatan Tamansari Kota Tasikmalaya, untuk tahap awal (pertimbangan biaya) diambil sample secara proporsional random sampling sejumlah 5 keluarga ( 5 rumah) untuk dijadikan percontohan penerapan vertical garden sebagai alternative solusi ketersediaan pangan di tengah kondisi pandemic covid-19.

Tahapan proses pelatihan akan mengacu pada tiga tahapan utama dalam pelatihan yakni penentuan kebutuhan pelatihan, desain program pelatihan, dan evaluasi program pelatihan ${ }^{5}$.

1. Penentuan kebutuhan pelatihan (assessing training needs) yaitu menilai kebutuhankebutuhan pelatihan bagi calon peserta. Tujuan penentuan kebutuhan pelatihan agar pelatihan lebih efektif. Kegiatan ini akan dilakukan dengan cara wawancara dilakukan pelatihan. Teknik assessing training needs adalah:

a) General treatment need, yaitu penilaian kebutuhan pelatihan terkait dengan pembuatan dan pemasangan vertical garden di Lingkungan Kelurahan Setiamulya.

b) Oversable performance discrepancies, yaitu penilaian kebutuhan pelatihan yang didasarkan pada hasil pengamatan terhadap berbagai permasalahan yang dihadapi.

c) Future human resources neeeds, yaitu penilaian keperluan pelatihan ini berdasarkan pada kesenjangan antara keadaan saat ini dengan ekspektasi pemanfaatan vertical garden.

2. Mendesain program pelatihan (desaigning a training program) yaitu kegiatan pelatihan. Sesuai rancangan awal, desain program akan berorientasi pada pendekatan andragogy dengan metode workshop pembuatan dan pemasangan vertical garden dengan prinsip memberi motivasi para peserta pelatihan, mengejar ketrampilan-ketrampilan yang spesifik, konsisten dangan isi pelatihan, peserta berpartisipasi aktif, memberikan 
kesempatan untuk perluasan ketrampilan, memberikan feedback, mendorong dari hasil pelatihan dapat dipraktikkan langsung di dalam pekerjaan, dan efektivitas dari segi biaya.

3. Langkah pelatihan dengan pendekatan kaji tindak (action research):

a) Siklus Pertama

1) Orientasi pelatihan yaitu memberi arahan dan penetapan target tujuan pelatihan supaya lebih efektif dan peserta dapat berpartisipasi dengan aktif.

2) Pemaparan materi tentang apa itu vertical garden, prosedur pembuatannya, serta pemanfaatannya.

3) Workshop pembuatan vertical garden.

4) Refleksi ketercapaian target pelatihan siklus pertama

b) Siklus kedua

1) Penyampaian hasil refleksi siklus pertama kepada peserta pelatihan

2) Worshop perbaikan dan penyempurnaan pembuatan vertical garden.

3) Refleksi ketercapaian target pelatihan siklus kedua

Evaluasi efektifitas program (evaluating training program effectivenees) yaitu evaluasi yang bertujuan untuk memperbaiki kekurangan pelatihan. Tujuan dari tahapan ini adalah untuk menguji apakah pelatihan tersebut efektif di dalam mencapai sasaran-sasarannya yang telah ditetapkan. Ukuran efektivitas pelatihan akan diukur berdasarkan kriteria reaction, learning, behaviors, organizational result, dan cost efectivity.

\section{HASIL}

Pelaksanaan pengabdian kepada masyarakat ini menghasilkan beberapa hal yang merupakan tujuan awal pengabdian. Hasil tersebut terdiri dari Terbinanya masyarakat yang mengerti mengenai konsep vertical garden dalam memanfaatkan lahan yang sempit, serta Terbentuknya masyarakat yang dapat membuat, mengembangkan, serta memanfaatkan vertical garden untuk kebutuhan pangan sehari-hari ditengah pandemic covid-19 ini.

\section{PEMBAHASAN}

Kegiatan pelatihan pemberian materi menganai Vertical Garden sangan disambut baik dan antusias oleh Masyarakat Perumahan Garuda Mas Resident. Hal Tersebut tercermin dari jumlah peserta yang mencapai 30 orang. Dalam pemaparan tersebut dijelaskan mengenai konsep-konsep vertical garden yang selama ini ada, dan layak untuk dikembangkan di lokasi sebagai alternatif solusi kebutuhan pangan didalam masa pandemic covid-19. Sejalan dengan pengabdian yang dilaksakan oleh tim dari Universitas Ahmad Dahlan, menyebutkan bahwa pelatihan vertical garden mendorong Ibu-lbu untuk mendapatkan ilmu yang komperhensif dan lebih bersemangat untuk menerapkannya disekitar lingkungannya ${ }^{6}$. Warga msyarakat selepas pemberian materi menjadi lebih terampil dan terbina dalam memanfaatkan lahan sempit untuk dijadikan vertical garden ${ }^{7}$. Dengan diadakannya kegiatan pelatihan pemberian materi tersebut masyarakat lebih faham dan lebih terbina dalam konsep vertical garden dalam memanfaatkan lahan yang sempit di perkotaan.

Setelah rampungnya kegiatan pelatihan yaitu kegiatan pemberian materi mengenai vertical garden, maka kegiatan selanjutnya adalah kegiatan praktek langsung (workshop) bagaimana cara pembuatan dan pengembangan vertical garden tersebut. Dalam kegiatan ini masyarakat dilatih untuk dapat membuat dan mengembangakan vertical garden di lingkungannya. Masyarakat sangat antusias dalam mengikuti kegiatan ini, mereka dengan gotong royong membangun dan mengembangkan vertical garden di sekitar lingkungannya. Kegiatan selanjutnya adalah refleksi yang bertujuan untuk mengukur sejauh mana ketercapaian kegiatan pelatihan pematerian dan worshop yang sudah dilaksanakan, dengan tujuan mengukur ketercapaian kegiatan. Hasilnya adalah masyarakat menjadi terbagun pengetahuan dan skill-nya untuk dapat membuat dan mengembangkan vertical garden tersebut. Vertical garden juga bermanfaat sebagai sustainability, mengehmat energi, serta kenyamanan dan lingkungan yang tentunya sehat ${ }^{8}$.Penggunaan media tanam yang banyak 
pilihan bahkan yang ramah lingkungan menjadikan vertical garden mudah diadaptasai dan dikuasai oleh siapapun. Penggunaan vertical garden bisa dibuat gerakan ramah lingkungan dengan memakai botol plastic dan media lain yang bisa didaur ulang dan disusun secara vertical $^{9}$. Vertical Garden memiliki fungsi sebagai efek visual, membuat penanda khas dari lokasi, menimbulkan inspirasi, serta meningkatkan keanekaragaman hayati ${ }^{10}$. Diharapkan dengan pengetahuan dan kemampuan masyarakat dalam mengembangkan vertical garden tersebut dapat memberikan alternatif solusi dalam kebutuhan pangan ditengah kondisi pandemic covid-19.

\section{KESIMPULAN DAN SARAN}

Pada Era New Normal ini masyarakat diharapkan mampu untuk mencukupi segala kebutuhan kehidupannya ditengah segala keterbatasan, terutama akses pekerjaan yang terbatas, yang menyebabkan penghasilan menjadi menurun, dan tentunya daya beli juga ikut menurun. Penggunaan Vertical Garden dapat menjadi solusi ditengah daya beli masyarakat yang menurun dapat disiasati dengan hasil produksi vertical garden dalam bentuk pangan untuk alternative kebutuhan pangan sehari-hari. Seluruh rangkaian kegiatan yang telah dilaksanakan dari awal kegiatan yaitu pelatihan pematerian mengenai vertical garden semoga dapat menambah wawasan dan pengetahuan mengenai vertical garden. Sedangkan worshop pembuatan dan pengembangan vertical garden semoga dapat memberikan pengetahuan, wawasan, serta dapat mengasah kemampuan keterampilan atau skill dalam pembuatan dan pengembangan vertical garden di lingkungan sekitar rumah. Dengan pengetahuan, wawasan, serta kemampuan keterampilan atau skill tersebut, diharapkan masyarakat dapat mengembangkan sendiri mengenai konsep vertical garden tersebut kedepannya. Saran dalam kegiatan pengabdian ini adalah dilanjutkannya bentuk pengabdian sejenis di lokasi-lokasi lain, guna membantu ketercukupan kebutuhan pangan masyarakat yang lebih banyak lagi.

\section{UCAPAN TERIMA KASIH}

Ucapan terima kasih diberikan kepada Bapak Rektor Universitas Siliwangi, Ketua LPM Universitas Siliwangi, Para Dosen di Universitas Siliwangi dan seluruh Staf Tenaga Kependidikan, Penyuluh Pertanian di Kota Tasikmalaya, serta Warga di Perumahan Garuda Mas Residence Setiamulya Kota Tasikmalaya yang telah melaksanakan dan mendukung kegiatan Pengabdian Kepada Masyarakat ini.

\section{DAFTAR PUSTAKA}

Widiastuti, Ratih, dkk (2014). Evaluasi Termal Dinding Bangunan Dengan Vertical Garden. Jurnal PPKM UNSIQ. Hal. 1-12., 2014.

Syarifudin. (2013). Pencemaran Lingkungan dalam Perspektif Fiqih. Jurnal Hukum Islam, Vol. XIII No. 1 Juni $2013: 40-63$.

Widiastutih, R dkk (2014). Kenyamanan Termal Bangunan Dengan Vertical Garden Berdasarkan Standar Kenyamanan Mom \& Wiesborn. Jurnal PPKM UNSIQ. 8, (1) 1-12.

Wong N.H, dkk (2010). Thermal Evaluation Of Vertical Greenery System For Building Walls. Building and Environment, 45 (2010) 663-672.

Gomes, FC. (2003). Manajemen Sumber Daya Manusia. Yogyakarta. Penerbit Andi.

Utami, Inggita, dkk. (2020). Pelatihan Vertical Garden dalam Optimalisasi Lorong Sayur di Lahan Sempit Kecamatan Ngampilan Yogyakarta. Jurnal Pemberdayaan: Publikasi hasil Pengabdian Kepada Masyarakat. Vol. 4, No. 2, Agustus 2020, Hal. 159-166.

Arum, Hany Maesyafitri, dkk. (2019). Pemanfaatan Barang Bekas Botol Plastik dalam pembuatan Vertical Garden di Wilayah Lamtoro Pamulang Timur. Proshiding Seminar Nasional Pengabdian Masyarakat LPPM Universitas Muhamamdiyah Jakarta. 06-UMJPE. Hal. 1-5. E-ISSN: 2714-6286. 
Rashid, R. dkk. (2010). Natural Green Application Technology On Building In Dense Dhaka City Is Provide A Sustainable, Energy Saving, Comfortable and Healthy Environment. Research Journal, University Technology Malaysia.

Budiarto, Slamet (2013). Inspirasi Design dan Cara Membuat Vertical Garden. Jakarta: Agro Media Pustaka.

Prakoso, Christianto, dkk. (2018). Perancangan dan Evaluasi Design Vertical Garden Bertema "Golden Year". Jurnal IImu Pertanian ARGIC. Vol. 30, No. 1, Juli 2018: 33-42. 


\section{LAMPIRAN}

\section{Lampiran 1 (Rangkaian Kegiatan PKM)}

Tabel 1. Rangkaian Kegiatan PKM

\begin{tabular}{|c|c|c|}
\hline No. & Tahapan & Progres Kegiatan \\
\hline 1 & Mengurus Perizian & Sudah Dilaksanakan \\
\hline 2 & $\begin{array}{l}\text { Penentuan kebutuhan pelatihan } \\
\text { (assessing training needs) }\end{array}$ & Sudah Dilaksanakan \\
\hline 3 & $\begin{array}{l}\text { Mendesain program pelatihan } \\
\text { (desaigning a training program) }\end{array}$ & Sudah Dilaksanakan \\
\hline 4 & Pelaksanaan pelatihan Siklus Pertama & Sudah Dilaksanakan \\
\hline 5 & Refleksi Pelatihan Siklus Pertama & Sudah Dilaksanakan \\
\hline 6 & $\begin{array}{l}\text { Pelaksanaan pelatihan Siklus Kedua } \\
\text { (Workshop) }\end{array}$ & Sudah Dilaksanakan \\
\hline 7 & Refleksi Pelatihan Siklus Kedua & Sudah Dilaksanakan \\
\hline 8 & Penyunan laporan & Sudah Dilaksanakan \\
\hline 9 & Penyusunan produk pengabdian (artikel) & Sudah Dilaksanakan \\
\hline
\end{tabular}




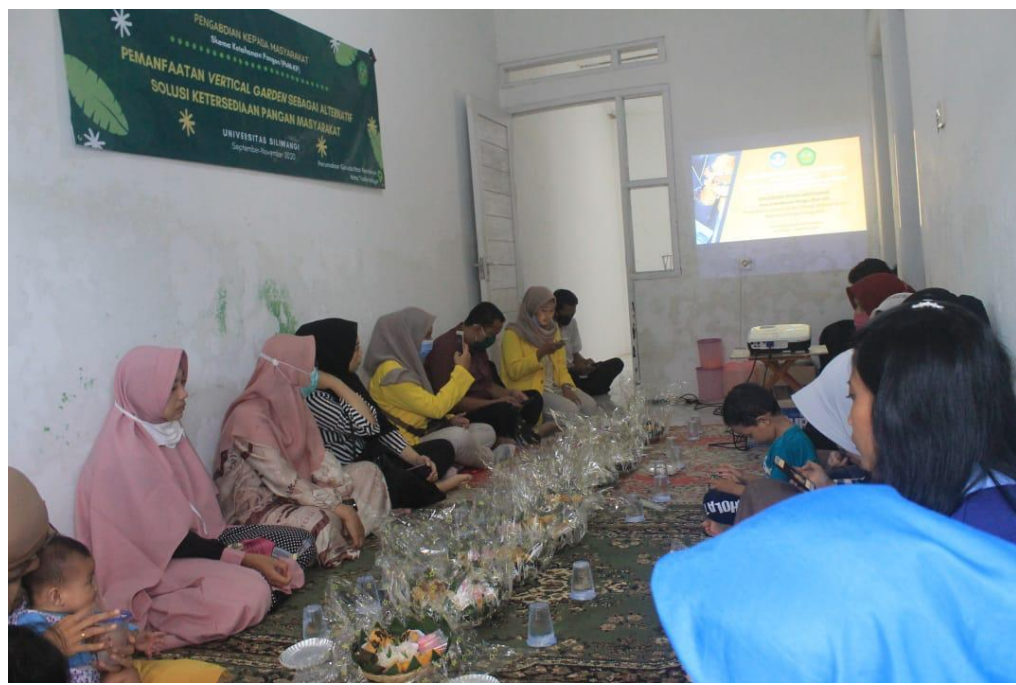

Sumber: Dokumentasi Kegian PKM 2020

Gambar 1. Kegiatan Pematerian Vertical Garden

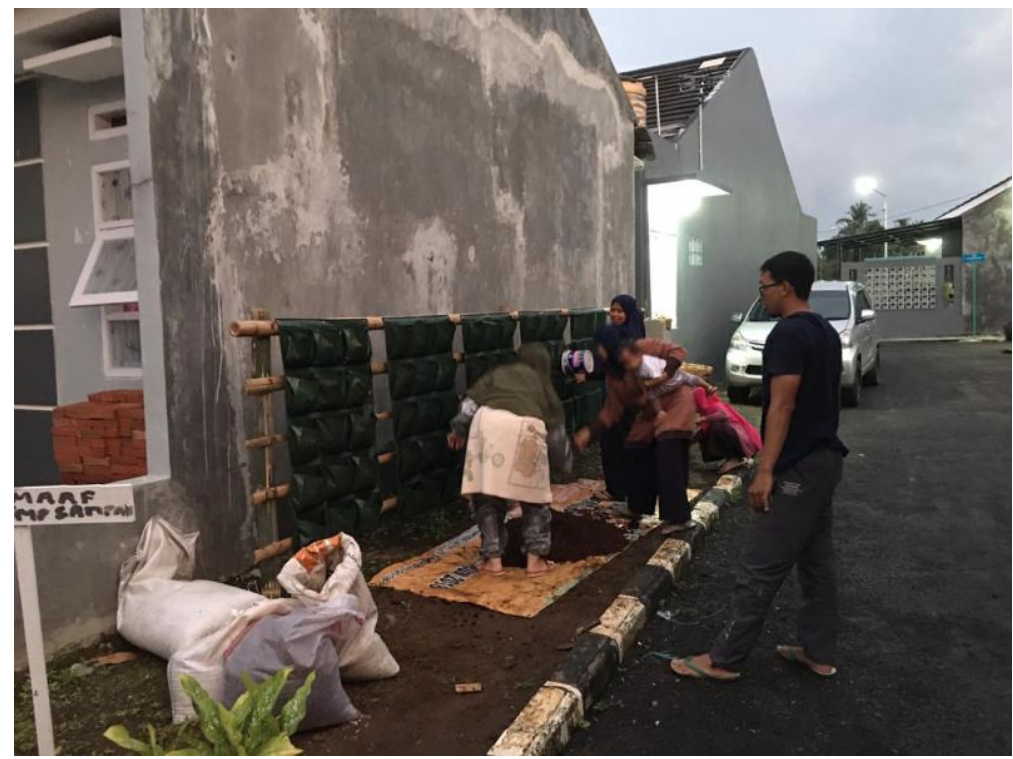

Sumber: Dokumentasi Kegian PKM 2020

Gambar 2. Kegiatan Workshop dan Pemeliharaan Vertical Garden 